Review

\title{
Topies in Transcriptional Control of Lipid Metabolism: from Transcription Factors to Gene-Promoter Polymorphisms
}

\author{
Werner G. Bergen ${ }^{\varpi}$ and Derris D. Burnett \\ Program in Cellular and Molecular Biosciences, Department of Animal Sciences, Auburn University, Alabama, 36849-5415, \\ USA. \\ $\triangle$ Corresponding author: Dr. W.G. Bergen, Department of Animal Sciences, Auburn University, AL 36840-5415; Tel +1334-844-1504; FAX \\ +1334 844-1519; E-mail: bergewg@auburn.edu \\ (c) Ivyspring International Publisher. This is an open-access article distributed under the terms of the Creative Commons License (http://creativecommons.org/ \\ licenses/by-nc-nd/3.0/). Reproduction is permitted for personal, noncommercial use, provided that the article is in whole, unmodified, and properly cited.
}

Published: 2013.10 .20

\begin{abstract}
The central dogma of biology (DNA>>RNA>>Protein) has remained as an extremely useful scaffold to guide the study of molecular regulation of cellular metabolism. Molecular regulation of cellular metabolism has been pursued from an individual enzyme to a global assessment of protein function at the genomic (DNA), transcriptomic (RNA) and translation (Protein) levels. Details of a key role by inhibitory small RNAs and post-translational processing of cellular proteins on a whole cell/global basis are now just emerging. Below we emphasize the role of transcription factors (TF) in regulation of adipogenesis and lipogenesis. Additionally we have also focused on emerging additional TF that may also have hitherto unrecognized roles in adipogenesis and lipogenesis as compared to our present understanding. It is generally recognized that SNPs in structural genes can affect the final structure/function of a given protein. The implications of SNPs located in the non-transcribed promoter region on transcription have not been examined as extensively at this time. Here we have also summarized some emerging results on promoter SNPs for lipid metabolism and related cellular processes.
\end{abstract}

Key words: Adipogenesis, Lipogenesis, Transcription factors, SNP, Gene Regulation

\section{Introduction}

The central dogma of biology [1] as coined by Francis Crick not only explained the sequential interactions of major cellular processes for replication and to synthesize proteins, but remains an important scaffold for our understanding of gene regulation. The concepts of transcriptional or pre-translational controls (related to gene expression), translational controls (related to protein biosynthesis) and post translational processes (related to protein processing and folding) are reflected in evolution of the contemporary knowledge base for regulation of gene expression and enzymatic activity [2]. Much of our current understanding of gene regulation, protein synthesis and processing arose from studies of individual genes/enzymes considered rate limiting or very critical within a given pathway [3] (often related to rapid hormone responsiveness); however, more recently workers have been able to measure expression of genes (mRNA abundance) and the proteome expression utilizing DNA-micro-arrays [4], isoelectric focusing (IEF) and capillary electrophoresis and MALDI-mass spectroscopy $[5,6]$. Transcription is the starting point for eventual protein synthesis and function and is followed by other post-transcriptional processes. DNA polymorphisms (SNP) may also modify activity of an enzyme via structural modifications; such polymorphisms may be present in non-coding (introns) and coding (exons) regions of 
the structural gene giving rise to different alleles of a given gene. Additionally in the core promoter and enhancers/response elements $\left(5^{\prime}\right.$ upstream from transcription start site) SNPs in regulatory sites or cis response elements may modify gene expression [7].

Post-transcriptional processes include translational control, protein processing and post-translational folding $[2,8]$. Newer emerging translational control mechanisms include non-coding microRNA (miRNA), which are now emerging as a major factor in the regulation of mRNA utilization for translation, $[9,10]$. Processed miRNA are specific inhibitors of translation which do not participate in transcription per se. An example of a regulatory loop of transcription and subsequent translation (endogenous RNA interference pathway in post-translational regulation) has been described where an intron of a given structural gene contains a complete sequence for an unprocessed specific miRNA [11]. Hence as the rate of transcription for such a gene increases (as would be noted via micro-array gene expression studies), a countervailing regulatory mechanisms is present to possibly attenuate translation and hence protein expression possibly leading to erroneous conclusions about the regulating effects of transcription [11]. Other pre-translational gene expression regulatory events include snRNA processing, nucleosome remodeling, histone methylation, acetylation and ubiquination [12].

\section{Adipose Tissue}

Adipose tissue (AT) is present in all mammals to store excess nutritional energy in the form of triacylglycerol $[13,14,15]$ such that during periods when nutrient availability is low or energy demand is high this energy can be mobilized and used as a readily available energy source (Thrifty gene hypothesis). Once thought of as simply a storage depot for excess dietary energy with lesser roles as a cushion and insulator in the body, we now know that AT participates in whole body endocrine, paracrine, and autocrine signaling networks that play critical roles in energy homeostasis, immune function and in reproductive processes $[16,17]$. AT also serves as the primary site for de novo fatty acid synthesis in livestock species such as pigs, and ruminant species; but much less so for humans and rodents [18]. The contributions of AT to whole-body energy metabolism and cell-signaling in humans and animals have begun to garner much more appreciation. One of the highest research impact areas has been the discovery and characterization of specific transcription factors (TF) and adipokines in the metabolic processes of adipogenesis, lipogenesis, triacylglycerol (TAG) deposition, fat mobilization, transport and fatty acid oxidation. The role of TFs and adipokines as components of the regulatory network of lipid metabolism (for adipogenesis, lipogenesis and de novo fatty acid synthesis) has been well established and extensively reviewed $[19,20]$. Here we present a short overview to set the stage for some newer emerging processes that affect transcriptional control.

\section{Adipogenesis}

Adipogenesis is an inclusive term that describes the cellular events responsible for the commitment of pluripotent stem cells to the adipocyte lineage to form pre-adipocytes, and the proliferation and differentiation of these pre-adipocytes into mature adipocytes capable of assimilating and storing lipids as well as responding to various external stimuli [21,22]. De novo AT development occurs in multiple distinct sites in animals including subcutaneous and visceral fat depots, kidney, and heart and between and within skeletal muscles. Adipogenic events are accompanied by functional and morphological changes that occur at the cellular level and lead to the formation and accretion of distinct AT depots in vivo [23,24]. Adipose tissue expansion can be attributed to adipogenic processes that lead to hyperplastic and hypertrophic expansion of the depot during the course of growth and development. Numerous detailed studies on the stages and indices of adipogenesis have been conducted due to the agricultural and biomedical ramifications of AT biology and pathology, particularly with respect to excessive AT accretion. Much of our understanding of these events has been established using in-vitro techniques and various cell-lines (Reviewed in [24, 25]).

The process of adipogenesis occurs as a series of temporally regulated events that are responsible for the development and expansion of AT in specific depots. Several studies have helped to determine that this process is under the control of specific transcription factors (TFs) that respond to environmental and developmental cues to establish and maintain adipogenic gene-expression paradigms [26-29, 30]. The gene products targeted by these TFs include metabolic proteins, lipid transport proteins, and those that impart hormone responsiveness on the adipocyte [18, 31]. The ultimate fate of adipocyte precursor cells is determined by several factors including the immediate endocrine/paracrine environment, adhesion to the extracellular matrix, the specific milieu of transcription and regulatory factors, and nutrient availability $[22,25,32,33]$. The balances of pro- and anti-adipogenic factors present in the local environment dictate the commitment to, and progression through 
adipogenic cascades [34].

Transcription factors have been identified which regulate/modulate adipogenesis as well as de novo fatty acid synthesis and lipogenesis (formation of fat) in differentiated adipose tissues. Much of this work continues to be repeatedly reviewed and updated. Findings have indicated that Peroxisome proliferator activated receptor gamma (PPAR $\gamma)$, Liver $X$ receptor (LXR), Sterol regulatory element binding protein/factor-1c (SREBP-1c) and MLX interacting protein-like (MLXIPL; formerly Carbohydrate response element binding protein, ChREBP) are major regulatory factors both in adipogenesis, pre-adipocyte differentiation and fat deposition [22, 35, 36]. Numerous other transcription factors have additional important roles in overall regulation of adipogenesis and lipogenesis [37]. Many species (principally herbivores) utilize acetate as the primary precursor for de novo fatty acid synthesis [18] and here the roles of ATP-citrate lyase and MLXIPL would be less significant. A discussion of some of the well-characterized adipogenic TFs and other markers of differentiation follows below.

\section{Peroxisome Proliferator Activated Receptors (PPARs)}

PPARs belong to a family of ligand-dependent nuclear receptor transcription factors and the role of these TFs as master regulators of adipogenesis is supported by both in vivo and in vitro studies. Members of the PPAR family included PPAR-alpha, PPAR-beta/delta, and PPAR-gamma (PPAR- $\gamma$ ).

In terms of adipogenesis, the regulatory transcription cascade is centered on the expression of PPAR- $\gamma[21,38-40]$. PPAR- $\gamma$ is a lipid activated nuclear receptor that is considered to be both necessary and sufficient to initiate the entire program of adipogenesis [21, 38, 40, 41]. PPAR- $\gamma$ is expressed as two isoforms designated PPAR- $\gamma 1$ and PPAR- $\gamma 2$, which are derived from alternative promoter regions in the same gene. PPAR- $\gamma 2$ is identical to PPAR- $\gamma 1$ with the exception of an additional 30 amino acid segment at the N-terminus of the peptide [42]. While the PPAR- $\gamma 1$ isoform is expressed in various tissues, PPAR- $\gamma 2$ expression appears to be restricted to AT.

Thiazolidinediones (TZDs) are a class of pharmacological compounds that have insulin-sensitizing effects and have been shown to be ligands for PPAR- $\gamma$ $[39,43,44]$. These compounds are effective at improving insulin sensitivity in part by the PPAR- $\gamma$ induced changes in expression of lipid metabolism and adipogenesis related genes including glucose transporters, fatty acid binding proteins (FABPs), lipogenic enzymes and lipoprotein lipase and other PPAR- $\gamma$ targets [44]. TZDs have been shown to effectively induce adipogenesis in several in vitro systems including rodent, human, bovine, and porcine adipose tissue stromal-vascular cell cultures [45]. While these compounds are widely used in treatment of type-2 diabetes, their usefulness in livestock species to improve quality of muscle foods has garnered recent attention and warrants further consideration.

\section{CCAAT-Enhancer-Binding Proteins (C/EBPs)}

C/EBPs are a family of TFs, which consists of six members (C/EBP a to C/EBP $\delta$ ). The expression of each of the C/EBP proteins occurs at specific time points during adipogenesis, indicative of their distinct roles in the process. CEBP/ $\alpha$ and $C E B P / \delta$ are expressed early in adipogenesis and are responsible for initiating the differentiation of preadipocytes through eventual activation of PPAR-ү. Tang et al. [46] provided evidence for the role of CEBP/ $\beta$ in the adipogenic process. Using 3T3-L1 cells and murine embryonic fibroblasts (MEFs) they determined that $\mathrm{CEBP} / \beta$ is involved in regulating mitotic clonal expansion of preadipocytes which is required for adipogenesis to occur, and precedes the expression of the TFs that give rise to the mature adipocyte phenotype [47].

$\mathrm{C} / \mathrm{EBPa}$ is also known as a master regulator of adipogenesis and cooperates with PPAR- $\gamma$ to establish and maintain the adipogenic program. In cell culture, expression of C/EBPa occurs relatively late during adipogenesis after the induction of PPARY $[48,49]$. Rosen et al. [50] determined that while important, $\mathrm{C} / \mathrm{EBPa}$ is not required to drive adipogenesis in the same manner that PPARY does. This suggests that PPARY and C/EBPa induce adipogenesis using a single pathway with PPARY playing the predominant role and C/EBPa acting in a feed-forward loop to drive PPAR- $\gamma$ expression. Terminal adipogenesis appears to be dependent on $\mathrm{C} / \mathrm{EBPa}$ because failure to express C/EBPa results in insulin resistance and failure to accumulate white adipose tissue (WAT) in vivo suggesting that $\mathrm{C} / \mathrm{EBPa}$ is required to maintain PPARY expression which in turn contributes to insulin sensitivity and AT accretion [48].

\section{MLX interacting protein-like protein}

MLX interacting protein-like (MLXIPL; also known as carbohydrate response element binding protein, ChREBP) is a regulatory transcription factor that enhances the expression of lipogenic enzymes in response to cellular carbohydrate metabolite levels [35]. Studies have shown that targeted disruption of MLXIPL results in aberrant lipid metabolism in vitro and in vivo [51]. Further work showed that mRNA 
levels for all of the major lipogenic enzyme genes, as well as for hepatic pyruvate kinase (PKLR), were significantly lower in MXLIPL-null mice fed a high-starch diet compared to those in WT mice. In addition these mice showed decreased liver triacylglycerol and total body lipogenesis providing evidence for a significant role of MLXIPL in glucose regulation of lipid metabolism in vivo [51-53]. Ishii et al. [54] also provided evidence for the direct role of MXLIPL in lipogenic gene expression utilizing various reporter-constructs containing acetyl-CoA carboxylase (ACC), fatty acid synthase (FAS), or PKLR promoters. Additionally, MXLIPL was responsive to glucose when transfected into WT but not MXLIPL null hepatocytes. In addition glucose transactivation of the constructs in MXLIPL null hepatocytes was restored by co-transfection with a functional MXLIPL expression plasmid [54].

\section{Sterol Regulatory Element Binding Proteins (SREBPs)}

Sterol Regulatory Element Binding Proteins (SREBPs) are helix-loop-helix TFs (bHLH) involved in adipogenesis and lipid metabolism; lipogenic genes possess a sterol response element for SREBP-1c binding [27, 55-57]. SREBP-2 has been recognized as a cholesterol 'sensing" molecule [56, 58]. Working with adipose rather than liver, Tontonoz et al. [27] described what was known as adipocyte determination and differentiation factor-1 (ADD1) as a basic helix loop helix domain containing protein which was expressed in brown adipose tissue and showed increased expression during differentiation of adipocytes in cell culture. They also showed that similar to SREBP-1, ADD1 could increase expression of the adipose fatty acid synthase (FAS gene), but was incapable of binding to other bHLH domain containing genes indicating the sequence specificity of this TF was high. The principal isoform of SREBPs that is insulin responsive and enhances liver and adipose lipogenesis is SREBP-1c. [59]. Multiple possible insulin signaling pathways have been implicated in SREBP-1c induction. The mammalian target of rapamycin complex 1 (mTORC1), a target of insulin signaling, has recently been implicated in the induction of SREBP-1c [60]. The SREBPs are unique proteins in that their nascent form is tethered in the endoplasmic reticulum and when their release by signal pathways is stimulated they are processed by highly specific proteases, released and processed before acting as a nuclear transcription factor [56].

\section{Delta-kinase homolog 1}

The differentiation of adipocyte progenitor cells to adipocytes is subject to induction by transcriptional activators and suppression by transcriptional inhibitors [40]. The balance of inhibitors and activators is responsible for the rate and extent of adipogenesis among a population of progenitor cells. Delta-like kinase homolog 1 (DLK-1; also known as preadipocyte factor or Pref1) ) is a member of the epidermal growth factor-like protein family that was identified during differential screening of cDNAs expressed in differentiating murine 3T3-L1 adipocytes [61,62]. DLK-1/Pref-1 expression is high in preadipocytes and is down-regulated during the conversion of preadipocytes to adipocytes. Smas and Sul [61] reported that DLK-1 was important in maintaining the preadipocyte state and that overexpression of DLK-1or addition of the soluble ectodomain of DLK-1 to 3T3-L1-cell culture was sufficient to prevent adipogenic conversion in these cells. DLK-1 also has an inhibitory effect on expression of PPAR- $\gamma$ and CEBP/a. The role of DKL-1 as an anti-adipogenic TF has since been characterized in beef cattle and other livestock species with the bovine DLK-1 gene being mapped to chromosome 21q24 [63] and its importance in adipogenesis particularly in the development of intramuscular fat has recently gained attention.

Multipotent mesenchymal cells (MSC) commit and differentiate into various cell lineages including myocytes, adipocytes, osteoblasts, and chondrocytes [15]. DLK-1 is capable of regulating both the commitment of multipotent MSCs to a particular cell lineage and the maintenance of these committed cells in an immature state [64]. Using DLK-1 knockout and transgenic murine embryonic fibroblasts, Wang and Sul [64] were able to elucidate some details on DLK-1 mechanism of action. They showed that DLK-1 inhibits the differentiation of adipocytes by upregulating the expression of SRY-sex determining region Y-box 9 (Sox9) which is expressed in progenitor cells that give rise to osteocytes and chondrocytes and promotes chondrogenic commitment. Cells that eventually give rise to chondrocytes and adipocytes come from a common source of MSCs; Sox9 inhibits adipogenesis while promoting chondrogenesis in this pool of progenitor cells. It was concluded that down regulation of Sox9 is required for adipocyte differentiation and that DLK-1 inhibits adipocyte differentiation through upregulation of Sox9 expression. Sox9 directly binds $\mathrm{C} / \mathrm{EBP} \beta / \delta$ promoters and inhibits their expression thereby preventing adipocyte differentiation. Additionally authors showed that DLK-1 promotes chondrogenic determination of MSCs using a combination 
of DLK-1 null and overexpression mouse models. This provides evidence that DLK-1 directly targets and promotes Sox9 expression and that DLK-1 is capable of inhibiting MSC differentiation into adipocytes and directing them to chondrogenic lineage [65]. Other workers have studied the relationship between Forkhead box-2 (Foxa-2) and DLK-1. Both DLK-1 and Foxa-2 expression is increased by growth hormone $(\mathrm{GH})$, a potent adipogenesis and fat deposition inhibitor, and Foxa- 4 appears to mediate the GH dependent inhibition of adipogenesis [66]. There is further evidence that Foxa-2 attenuates adipocytes differentiation via direct activation of DLK-1 expression [66]. As a further confirmation of Foxa- 4 as an adipogenesis inhibitor, in hyper-insulinemic states such as obesity, Foxa-4 is not expressed in liver and adipose tissue. In addition Foxa-2 is phosphorylated by insulin/PI3K/Akt signaling which leads to the nuclear exclusion of this transcription factor [67].

\section{Zinc-finger protein 423}

Zinc finger protein 423 (Zfp423) is a recently identified regulator of adipogenesis and preadipocyte determination that unlike DLK-1, appears to promote the adipogenic events. Zfp423 is enriched in preadipogenic fibroblasts relative to non-adipogenic fibroblasts and its expression occurs upstream of PPARY [68]. Ablation of Zfp243 expression via short-hairpin RNA reduces PPAR $Y$ expression and impairs differentiation in 3T3-L1 preadipocytes. In undifferentiated cells, overexpression of Zfp423 results in PPAR-y induction and adipogenic differentiation of these cells (under appropriate differentiation conditions). Zfp423 has also been implicated as a regulator of neurologic development; therefore other specifying factors are likely to be involved in obtaining adipogenic competency in non-committed precursor cells. Taken together these data indicate a permissive role of Zfp243 in commitment of precursor cells to their adipogenic fate [68].

\section{Notch, Wnt and other novel inductive agents}

We described above the basic program for adipogenesis involving transcription factors $C / E R B ~ \beta / \delta$ to $\mathrm{C} / \mathrm{ERB}$ a, PPARY, followed by lipogenesis as determined in many cell culture studies [22, 29, 30, 55]. Upstream or early factors that provide initial signals for downstream adult cell development for adipogenesis are first involved with the transition of early stem cells to multipotent mesochymal cells, followed by step wise developmental changes to specific progenitor cells for preadipocytes. Chondrocytes and myocytes also arise from the mesodermal cell lineage and share early developmental events with adipo- cytes [22]. A competition between osteogenesis and adipogenesis for MSC occurs in bone and has received attention because of bone mineral loss in women [69]. During periods of mineral loss in bones, marrow stromal fat cells show an increased differentiation, growth and fat deposition. Factors that enhance osteogenesis strongly inhibit adipogenesis. Utilizing primary human bone marrow stromal cells, Ugarte et al. [69] showed that Notch signaling enhanced osteogenic differentiation but inhibited adipogenesis. Recent work utilizing epididymal white adipose tissue (WAT) and 3T3 and ST cell lines showed that Wnt 6, $10 \mathrm{a}$ and $10 \mathrm{~b}$ expression was lowered during adipogenesis in vivo and in vitro while ectopic expression of Wnt 6,10a, 10b inhibited adipogenesis in cell lines. These Wnt proteins however stimulated osteoblastogenesis in STcells [70]. The Wnt TF signaling involved in adipogenesis and osteogenesis is dependent on $\beta$-catenin [70]. Wnt ligands may also stimulate adipogenesis under different circumstances [71-73]. There is a growing list of additional transcription factors and ligands that appear to participate in the molecular regulation of adipogenesis $[10,74,75]$, including Krúppel like factors (KLF) a large family of zinc-finger TFs. These TFs appear to positively or negatively affect adipogenesis via crosstalk with C/ERB $\beta / \delta$ and PPARY [10, 75-80].

\section{Single nucleotide polymorphisms in lipo- genic gene promoters}

Single nucleotide polymorphism (SNP) based alleles in the structural genes may be utilized as genetic markers [81]; however such SNP depending on intron or exon location may also alter functional characteristics of gene products. SNP in regulatory elements in promoters or $5^{\prime}$ flanking regions could also alter expression of genes. Several groups noted that about $30 \%$ of SNP in gene regulatory regions may have functional consequences [82, 83]. Several examples for human and animal lipid metabolism are related below followed by a brief summary of very recent examples of SNP in gene regulatory-promoter regions.

While genome wide association studies based on high genome coverage SNP genotyping have related alleles/polymorphisms with phenotypes/traits (such as resistance or sensitivities to diseases, nutrient requirements, changes in metabolism) in both human and animal systems [81, 84, 85], the extent of polymorphisms / multiple alleles as assessed by SNP in the non-transcribed promoter/regulatory regions has been evaluated to a more limited extent. A SNP within a cis response element may weaken the binding of key transcription factors resulting in a lowered 
transcription. The $5^{\prime}$ (upstream) flanking promoter elements of many genes coding for enzymes involved in de novo fatty acid synthesis are characterized by multiple response elements. Among these are sites for the following transcription factors MLXIPL, Hepatic nuclear factor (HNF-4a), LXR, Retinoid X receptor (RXR), SREBP-1c, Specificity protein transcription factor $1 / 3(\mathrm{Sp} 1 / 3)$ and trans-Upstream stimulatory factor (USF) binding CCAAT/E box cis-promoter elements in fatty acid synthase [86]. As shown by Jump et al. [87] promoter binding of individual "lipogenic $\mathrm{TF}^{\prime \prime}$ may be relatively weak, but in concert these TF provide a strong impetus to transcription.

A g.841G>C SNP, located within a GC-rich region has been characterized in bovine fatty acid synthase [82]. These workers demonstrated that this SNP appears to affect Sp3 binding ability in bovine lactating mammary gland fatty acid synthase promoter, thereby affecting milk fatty acid content [83]. Milk fat in dairy cows on pasture may contain widely varying content of conjugated fatty acids (CLA) and stearoyl CoA desaturase (SCD) is involved in CLA synthesis in the bovine mammary gland. Keating et al [88] hypothesized SNP in critical promoter sites of bovine SCD may account for the observed high variations in milk CLA of animals on the same diet, however they found that sequences in segments of the $5^{\prime}$ region of SCD did not differ between high and low milk CLA producers. Lee et al. [89] detected a SNP at $-368 \mathrm{C}>\mathrm{T}$ in the promoter region of the acetyl CoA carboxylase $B$ isoform (rodent) with the $T$ allele showing significantly lower activity than the $\mathrm{C}$ allele. Other more recent work in other tissue systems for example has shown that a mutation in the cytochrome P450, family 11, subfamily A polypeptide (CYP11a1) promoter resulted in its down regulation of expression in adrenal, testis, ovary and placental tissues [90]. Additionally Richter et al. [91] using bio-informatics tools identified 3 SNPs in the ESR2 gene (encodes estrogen receptor beta protein) in humans. Utilizing a cell line, an ESR2 gene (3 SNPs singly or in combination) promoter luciferase reporter assays resulted in a fifty percent decline in ESR2 expression. Working with a Korean adult population, Kang et al. [92] associated SNP $\mathrm{s}$ in the leukemia inhibitory factor receptor gene promoter with schizophrenia.

\section{Conclusions and future research directions}

Fat cells may differentiate pre and postnatal. Hence well characterized cell lines and primary cell lines such as stromal vascular cells and collagenase digests of adipose tissues may all be extremely useful to continue ongoing paths of investigations in the molecular regulation of adipogenesis/differentiation in fat cells [93]. Additional understanding is needed on earlier, upstream molecular events of development in fat cells than the canonical adipogenic program principally derived with work from cell lines. Biopsies of preadipocyte containing tissue over time may be an excellent resource to identify upstream regulatory events. In all tissue samples obtained early in the development process, multi-potent as well as committed cells may be present. It may then be difficult to discern the role of specific transcription factors in molecular regulation in specific cell types or its precursors. In our view, comprehensive genome-wide data interpretation to obtain clearer understanding of the myriad of molecular regulatory factors for adipose development for health and disease studied with many different experimental systems will be incremental. At the present time relevant transcription factors are still being discovered and characterized $[70,76,79,80]$. In addition our technical abilities (such as LC-MS proteomic analysis, second generation sequencing) appear to surpass for the most part our interpretive capabilities. New computational approaches are thus required and development of multiple software resources is presently a major activity in the bioinformatics community.

\section{Summary}

Increasing understanding of regulation of lipid metabolism is being addressed utilizing molecular studies. Global gene expression profiling and genome wide association studies are being utilized extensively for diagnostic, predictive and functional studies at the genome level. These studies are especially valuable for studying control of lipid anabolism where most important genes are under transcriptional control. There appears to be ever burgeoning number of transcription factors to regulate lipid and cholesterol synthesis. The rate of expression may be critically affected by $\mathrm{SNP} /$ mutations in critical response elements of gene promoters. Putative effects of SNP in promoter response elements of lipogenenic enzymes can presently not be predicted, however lowering TF binding capacity may result in a mechanism for the regulation of the rate of gene expression. While from a human perspective, the overriding desire is to control fat deposition and cholesterol excess to maintain or improve health, a more complete understanding of lipid metabolism regulation in farm/food producing species will enable the production of lower fat but higher quality muscle food products.

\section{Conflict of Interest}

The authors have declared that no conflict of interest exists. 


\section{References}

1. Crick F. Central dogma of biology. Nature, 1970; 227: 561-563.

2. Carey MF, Smale ST. Transcriptional regulation in eukaryotes. Cold Springs Harbor, NY: Cold Spring Harbor Laboratory Press. 2000: 1-50.

3. Hanson RW, Reshef L. Regulation of phosphoenolpyruvate carboxykinase (GTP) gene expression. Ann Rev Biochem, 1997; 66:581-611.

4. Steibel JP, Wysocki M, Lunney JK, Ramos AM, Hu Z-l, Rothschild MF, Ernst CW. Assessment of a swine protein -annotated oligonucleotide microarray. Anim Gen, 2009; 40:883-893.

5. Desidero C, Rossetti DV, Ivarone F, Messana I, Castagnola M. Capillary electrophoresis-mass spectroscopy: recent trends in clinical proteomics. J Pharm Biomed Anal, 2010; 53:1161-1169.

6. Maccarone G, Turck CW, Martins-de Souza D. Shotgun mass spectroscopy workflow combining IEF and LC-MALDI-TOF/TOF. Protein J, 2010; 29: 99-102.

7. Pampin S, Rodriguez-Rey JC. Functional analysis of regulatory single nucleotide polymorphisms. Curr Opin Lipidol, 2007; 18:194-198.

8. Kamath KS, Vasavada MS, Srivastava S. Proteomic databases and tools to decipher post-translational modifications. J Proteomics, 2011;75: 127-144.

9. McGregor RA, Choi MS. microRNAs in the regulation of adipogenesis and obesity. Curr Mol Med , 2011; 11:304-316.

10. Romao JM, Jin W, Dodson MV, Hausman GJ, Moore SS, Guan LL. MicroRNA regulation in mammalian adipogenesis. Exp Biol Med, 2011; 236:997-1004.

11. Najafi-Shoushtari SH, Kristo F, Li Y, Shioda T, Cohen DE, Gerszten RE, Näär AM. MicroRNA-33 and the SREBP host genes cooperate to control cholesterol homeostasis. Science, 2010; 328:1566-1569.

12. Qureshi IA, Mehler MF. The emerging role of epigenetics in stroke: II. RNA regulatory circuitry. Arch Neurol, 2010; 67:1435-1441.

13. Ashrafi K. Obesity and the regulation of fat metabolism. WormBook, 2007 Mar 9;: 1-20.

14. Sun K, Kusminski CM, Scherer PE. Adipose tissue remodeling and obesity. J Clin Invest, 2011; 121:2094-101.

15. Gesta S, Tseng YH, Kahn CR. Developmental origin of fat: tracking obesity to its source. Cell, 2007; 131:242-256.

16. Kim S, Moustaid-Moussa N. Secretory, endocrine and autocrine/paracrine function of the adipocyte. J Nutr, 2000; 130: 3110S-3115S.

17. Waki H, Tontonoz P. Endocrine functions of adipose tissues. Annu Rev Pathol, 2007; 2:31-56.

18. Bergen WG, Mersmann HJ. Comparative aspects of lipid metabolism: impact on contemporary research and use of animal models. J Nutr, 2005; 135:2499-2502.

19. Sierebaek R, Mandrup S. Transcriptional networks controlling adipocyte differentiation. Cold Spring Harbor Symp Quant Biol ,2011; doi:10.1101/sqb.2011.76.010512.

20. White UA, Stephens JM. Transcriptional factors that promote formation of white adipose tissue. Mol Cell Endocrinol , 2010; 318:10-14

21. Rosen ED, Walkey CJ, Puigserver P, Spiegelman BM. Transcriptional regulation of adipogenesis. Genes Dev, 2000; 14: 1293-307.

22. Hausman GJ, Dodson MV, Ajuwon K, Azain M, Barnes K, Guan LL, Jiang Z, Poulos SP, Sainz RD, Smith S, Spurlock M, Novakofski J, Fernyhough ME, Bergen WG. Board invited review: The biology and regulation of preadipocytes and adipocytes in meat animals. J Anim Sci, 2009; 87: 1218-1246.

23. Hausman DB, DiGirolamo M, Bartness TJ, Hausman GJ, Martin RJ. The biology of white adipocyte proliferation. Obes Rev, 2001; 2: 239-254.
24. Novakofski J. Adipogenesis: usefulness of in vitro and in vivo experimental models. J Anim Sci, 2004; 82: 905-915.

25. Poulos SP, Dodson MV, Hausman GJ. Cell line models for differentiation: preadipocytes and adipocytes. Exp Biol Med, 2010; 235: 1185-1193.

26. Christy RJ, Yang VW, Ntambi JM, Geiman DE, Landschulz WH, Friedman AD, Nakabeppu Y, Kelly TJ, Lane MD. Differentiation-induced gene expression in 3T3-L1 preadipocytes: CCAAT/enhancer binding protein interacts with and activates the promoters of two adipocyte-specific genes. Genes Dev, 1989; 3:1323-1335.

27. Tontonoz P, Kim JB, Graves RA, Spiegelman BM. ADD1: a novel helix-loop-helix transcription factor associated with adipocyte determination and differentiation. Mol Cell Biol, 1993; 13:4753-4759.

28. Yeh WC, Cao Z, Classon M, McKnight SL. Cascade regulation of terminal adipocyte differentiation by three members of the C/EBP family of leucine zipper proteins. Genes Dev, 1995; 9:168-181.

29. MacDougald OA, Lane MD. Transcriptional regulation of gene expression during adipocyte differentiation. Annu Rev Biochem, 1995; 64:345-373.

30. Farmer SR. Transcriptional control of adipocyte formation. Cell Metab, 2006; 4:263-273.

31. Frühbeck G. A heliocentric view of leptin. Proc Nutr Soc, 2001; 60:301-318.

32. Scanes CG, Griminger P. Endocrine-nutrition interactions in birds. J Exp Zool Suppl, 1990; 4:98-105.

33. Poulos SP, Hausman DB, Hausman GJ. The development and endocrine functions of adipose tissue. Mol Cell Endocrinol, 2010; 323: 20-34.

34. Nuttail ME, Gimble JM. Controlling the balance between osteoblastogenesis and adipogenesis and the consequent therapeutic implications. Curr Opin Pharmacol, 2004; 4:290-294.

35. Strable MS, Ntambi JM. Genetic control of the de novo lipogenesis: role of diet induced obesity. Crit Rev Biochem Mol Biol, 2010; 45: 199-214.

36. Ducheix S, Lobaccaro JMA, Martin PG, Guillou H. Liver X receptor: an oxysterol sensor and a major player in the control of lipogenesis. Chem Phys Lipids, 2011; 164: 500-514.

37. Schmitt E, Ballou MA, Correra MN, DePeters LK, Loor JJ. Dietary lipid during transition period to manipulate subcutaneous adipose tissue peroxisome proliferator-activated receptor- $\gamma$ co-regulator and target gene expression. J Dairy Sci, 2011; 94: 5913-5935.

38. Wu Z, Puigserver P, Spiegelman BM. Transcriptional activation of adipogenesis. Curr Opin Cell Biol, 1999 ;11: 689-694.

39. Chinetti G, Fruchart JC, Steals B. Peroxisome proliferator-actived receptors (PPARs); nuclear receptors at the crossroads between between lipid metabolism and inflammation. Inflamm Res, 2000; 49: 497-505.

40. Rosen ED, Spiegelman BM. Molecular regulation of adipogenesis. Annu Rev Cell Dev Biol, 2000; 16:145-171.

41. Fernyhough ME, Okine E, Hausman G, Vierck JL, Dodson MV. PPARgamma and GLUT-4 expression as developmental regulators/markers for preadipocyte differentiation into an adipocyte. Domest Anim Endocrinol, 2007; 33:367-378.

42. Meirhaeghe A, Fajas L, Gouilleux F, Cottel D, Helbecque N, Auwerx J, Amouyel P. A functional polymorphism in a STAT5B site of the human PPAR gamma 3 gene promoter affects height and lipid metabolism in a French population. Arterioscler Thromb Vasc Biol, 2003; 23: 289-294.

43. Escher P, Wahli W. Peroxisome proliferator-activated receptors: insight into multiple cellular functions. Mutat Res, 2000; 448:121-138.

44. Weng JR, Chen CY, Pinzone JJ, Ringel MD, Chen CS. Beyond peroxisome proliferator-activated receptor gamma signaling: 
the multi-facets of the antitumor effect of thiazolidinediones. Endoc Relat Cancer, 2006; 13:401-413.

45. Hausman GJ, Barb CR, Dean RG. Patterns of gene expression in pig adipose tissue: transforming growth factors, interferons, interleukins, and apolipoproteins. J Anim Sci, 2007; 85: 2445-2456.

46. Tang QQ, Otto TC, and Lane MD. CCAAT/enhancer-binding protein $\beta$ is required for mitotic clonal expansion during adipogenesis. Proc Natl Acad Sci USA, 2003;100: 850-855.

47. Tang QQ, Otto TC, and Lane MD. Mitotic clonal expansion: a synchronous process required for adipogenesis. Proc Natl Acad Sci USA, 2003; 100:44-49.

48. Wu Z, Rosen ED, Brun R, Hauser S, Adelmant G, Troy AE, McKeon C, Darlington GJ, Spiegelman BM. Cross-regulation of C/EBP alpha and PPAR gamma controls the B transcriptional pathway of adipogenesis and insulin sensitivity. Mol Cell, 1999; 3:151-158

49. Salma N, Xiao H, Imbalzano AN. Temporal recruitment of CCAAT/enhancer-binding proteins to early and late adipogenic promoters in vivo. J Mol Endocrinol, 2006; 36:139-151.

50. Rosen ED, Hsu CH, Wang X, Sakai S, Freeman MW, Gonzalez FJ, Spiegelman BM. C/EBPalpha induces adipogenesis through PPARgamma: a unified pathway. Genes Dev, 2002; 16: 22-26.

51. lizuka K, Bruick RK, Liang G, Horton JD, Uyeda K. Deficiency of carbohydrate response element-binding protein (ChREBP) reduces lipogenesis as well as glycolysis. Proc Natl Acad Sci USA, 2004; 101:7281-7286.

52. lizuka K, Horikawa Y. ChREBP: a glucose-activated transcription factor involved in the development of metabolic syndrome. Endocr J, 2008; 55:617-624.

53. Iizuka K, Miller B, Uyeda K. Deficiency of carbohydrate-activated transcription factor ChREBP prevents obesity and improves plasma glucose control in leptin-deficient (ob/ob) mice. Am J Physiol Endocrinol Metab, 2006; 291:E358-364.

54. Ishii S, Iizuka K, Bruick RK, Liang G, Horton JD, Uyeda K. Deficiency of carbohydrate response element-binding protein (ChREBP) reduces lipogenesis as well as glycolysis. Proc Natl Acad Sci USA, 2004; 101:7281-7286.

55. Horton JD. Sterol regulatory element-binding proteins: transcriptional activators of lipid synthesis. Biochem Soc Trans, 2002; 30:1091-1095.

56. Horton JD, Goldstein JL, Brown MS. SREBPs: activators of the complete program of cholesterol and fatty acid synthesis in the liver. J Clin Invest, 2002; 109:1125-1131.

57. Schweizer M, Roder K, Zhang L, Wolf SS. Transcription factors acting on the promoter of the rat fatty acid synthase gene. Biochem Soc Trans, 2002; 30:1070-1072.

58. Adams CM, Goldstein JL, Brown MS. Cholesterol-induced conformational change in SCAP enhanced by Insig proteins and mimicked by cationic amphiphiles. Proc Natl Acad Sci USA, 2003; 100: 10647-10652.

59. Osborne TF. Sterol regulatory element binding proteins (SREBPs): key regulators of nutritional homeostasis and insulin action. J Biol Chem, 2000; 275: 32379-32382.

60. Lewis CA, Griffiths B, Santos CR, Pende M, Schulze A. Regulation of SREBP transcription factors by mTORC1. Bochem Soc Trans, 2011; 39:495-49.

61. Smas CM, Sul HS. Pref-1, a protein containing EFG-like repeats, inhibits adipocyte differentiation. Cell, 1993; 73:725-734.

62. Wang Y, Zhao L, Smas C, Sul HS. Pref-1 interacts with fibronectin to inhibit adipocyte differentiation. Mol Cell Biol, 2010; 30:3480-3492

63. Minoshima Y, Taniguchi Y, Tanaka K, Yamada T, Sasaki Y. Molecular cloning, expression analysis, promoter characterization, and chromosomal localization of the bovine PREF1 gene. Anim Genet, 2001; 32:333-339.
64. Wang Y, Sul HS. Pref-1 regulates mesenchymal cell commitment and differentiation through Sox9. Cell Metab, 2009; 3: 287-302.

65. Wang Y, Hudak H, Sul HS. Role of preadipocyte factor 1 in adipocyte differentiation. Clin Lipodol, 2010; 5:109-115.

66. Wolfrum C, Shih DQ, Kuwajima S, Norris AW, Kahn CR, Stoffel $\mathrm{M}$. Role of foxa-2 in adipocyte metabolism and differentiation. J Clin Invest, 2003; 112: 345-356.

67. Silva JP, von Meyenn F, Howell J, Thorens B, Wolfrum C, Stoffel M. Regulation of adaptive behavior during fasting by hypothalamic Foxa2. Nature, 2009; 462:646-651.

68. Gupta RK, Arany Z, Seale P, Mepani RJ, Ye L, Conroe HM, Roby YA, Kulaga H, Reed RR, Spiegelman BM. Transcriptional control of preadipocyte determination by Zfp423. Nature, 2010; 464: 619-623.

69. Ugarte F, Ryser M, Thieme S, Fierro FA, Navratiel K, Bornhaeuser $\mathrm{M}$, Brenner $\mathrm{S}$. Notch signaling enhances osteogenic differentiation while inhibiting adipogenesis in primary human bone marrow cells. Experimental Hematology, 2009; 37: 867-875.

70. Cawthorn WP, Bree AJ, Yao Y, Du B, Hemati N, Martinez-Santibanez G, MacDougald O. Wnt 6, Wnt10a, Wnt 10b inhibit adipogenesis and stimulate osteoblastogenesis through a $\beta$-catenin-dependent mechanism. Bone, 2011; doi:10.1016/j.bone.2011.08.010

71. Kanazawa A, Tsukada S, Kamiyama M, Yanagimoto T, Nakajima M, Maeda S. Wnt5b pathway partially inhibits canonical Wnt/beta-catenin signaling pathway and promotes adipogenesis in 3T3-L1 preadipocytes. Biochem Biophys Res Comm, 2005; 330: 503-510.

72. Nishizuka M, Koyanagi A, Osada S, Imagawa M. Wnt4 and Wnt5a promote adipocyte differentiation. FEBs Lett, 2008; 582: 3201-3205.

73. van Tienen FH, Laeremans H, van der Kellen CJ, Smeets HJ. Wnt $5 \mathrm{~b}$ stimulates adipogenesis by activating PPAR gamma and inhibiting the beta-catenin dependent Wnt signaling pathway together with Wnt5a. Biochem Biopys Res Comm, 2009; 387:207-211.

74. Lefterova MI, Steger DJ, Zhuo D, Qatanani M, Mullican SE, Tuteja G, Manduchi E, Grant GR, Lazar MA. Cell-specific determinants of peroxisome proliferator-activated receptor gamma function in adipocytes and macrophages. Mol Cell Biol, 2010; 30:2078-2089.

75. Lefterova MI, Zhang Y, Steger DJ, Schupp M, Schug J, Cristancho A, Feng D, Zhuo D, Stoeckert CJ Jr, Liu XS, Lazar MA. PPARgamma and C/EBP factors orchestrate adipocyte biology via adjacent binding on a genome-wide scale. Genes Dev, 2008; 22: 2941-2952.

76. McConnell BB, Yang VW. Mammalian Krúpplel-Like -factors in health and disease. Physiol Rev, 2010; 90:1337-1381.

77. Steger DJ, Lazar MA. Adipogenic hotspots: Where the action is. EMBO, 2011; 30: 1418-1419.

78. Christiancho AG, Lazar MA. Forming functional fat:a growing understanding of adipocyte differentiation. Nat Rev Mol Cell Biol, 2011; doi: 10.1038/nrm3198

79. Brey CW, Nelder MP, Hailemariam T, Gaugler R, Hashmi S. Krúppel like family of transcription factors: an emerging new frontier in fat biology. Int J Biol Sci, 2009; 5:622-636.

80. Zhang J, Bakheer R, Parhar RS, Huang C-H, Mahmood Hussain M, Pan X, Siddiqui SS, Hashmi S. Regulation of fat storage and reproduction by Krúppel-like transcription factor KLF3 and fat-associated genes in C. elegans. J Molec Biol, 2011; 411:537-553.

81. Wang L, Jia P, Wolfinger RD, Chen X, Zhao Z. Gene set analysis of genome-wide association studies: methodological issues and perspectives. Genomics, 2011; 98:1-8. 
82. Ordovas 1, Roy R, Pampin S, Zaragoza P, Osta R, Rodrigues-Rey JC, Rodellar C. The g.763G $>$ C SNP of the bovine FASN gene affects its promoter activity via $\mathrm{Sp}$-mediated regulation: implication for the bovine lactating mammary gland. Physiol Genomics, 2008; 34:144-148.

83. Roy R, Ordovas L, Zaragoza R, Romero A, Moreno C, Altarriba $\mathrm{J}$, Rodeller C. Assocaition of polymorphism in the bovine FASN gene with milk-fat content. Anim Genet, 2006; 37: 215-218.

84. Fridley BL, Biernacka JM.Gene set analysis of SNP data: benefits, challenges, and future directions. Eur J Hum Genet, 2011; 19: 837-843.

85. Davey JW, Hohenlohe PA, Etter PD, Boone JQ, Catchen JM, Blaxter ML. Genome-wide genetic marker discovery and genotyping using next-generation sequencing. Nat Rev Genet, 2011; 12:499-510

86. Wong RHF, Sul HS. Insulin signaling in fatty acid synthesis: a transcriptional perspective. Curr Opin Pharmacol, 2010; 10:684-691.

87. Jump DB, Thelen AP, Mater MK. Functional interaction between sterol regulatory element binding protein-1c, nuclear factor Y, and 3,5,3'-triiodothyronine nuclear receptors. J Biol Chem, 2001; 276: 34419-34427

88. Keating AF, Stanton C, Murphy JJ, Smith TJ, Ross RP, Cairns MT. Isolation and characterization of the bovine Stearoyl-CoA desaturase promoter and analysis of polymorphisms in the promoter regions of dairy cows. Mamm Genome, 2005; 16:184-193.

89. Lee AK, Kyriakou T, Weston AJ, O’Dell SD. Functional single-nucleotide polymorphism in acetyl-CoA carboxylase ACACB promoter DNA. Cell Biol, 2010; 29: 703-712.

90. Shih MC, Chiu YN, Hu MC, Guo IC, Chung BC. Regulation of steroid production: analysis of Cyp11a1 promoter. Mol Cell Endocrinol, 2011; 336: 80-84.

91. Richter S, Oesterreich S, Rae JM, Flockhart DA, Perumal NB, Skaar TC. Functional characterization of a genetic polymorphism in the promoter of the ESR2 gene. Horm Cancer, 2011; [Epub ahead of print].

92. Kang WS, Kim SK, Park JK, Cho AR, Park HJ, Chung JH, Jim JW. Association between promoter polymorphisms of the LIFR gene and schizophrenia with persecutory delusions in a Korean population. Mol Med Report, 2012; 5: 270-274.

93. Wu Z, McKnight SL, Spiegelman BM. Transcriptional activation of adipogenesis. Cell Biol, 1999; 11: 689-694.

\section{Author Biography}

Dr. Werner G. Bergen is Professor of Biochemistry and Nutrition in the Department of Animal Sciences at Auburn University (AU) and Professor-Emeritus in Animal Science at Michigan State University (MSU). For over four decades Dr. Bergen has studied biochemical and molecular-regulatory aspects of amino acids/protein and lipid metabolism and growth \& development principally in beef cattle and pigs with occasional work with laboratory rodents or cell lines in culture. His work has resulted in 133 peer-reviewed journal articles, numerous abstracts and state agricultural experiment station reports. He has also been cooperating in USDA sponsored multi-state research programs in muscle biology and growth (NCCC131) and food animal lipid metabolism (NCCC210) and has successfully super- vised/mentored $25 \mathrm{PhD}$ students and many Master of Science students at MSU and AU.

Mr. Derris D. Burnett is a PhD candidate in the area of growth, development and lipid metabolism of ruminants in the Department of Animal Sciences at Auburn University. He has completed his bachelor's and master's degrees at Tuskegee University. He has been conducting research on the molecular regulation of differentiation of intramuscular preadipocytes in grazing cattle. This work is being conducted to more fully understand the mechanism of potential intramuscular fat (marbling) deposition in cattle primarily raised and finished on pasture/forage systems. 